\title{
PHYSIOLOGICAL COMPARISON OF THE LONGI- TUDINAL AND CIRCULAR MUSCLES OF THE PREGNANT RAT UTERUS
}

\author{
Takuro OsA and Takashi KATASE \\ Department of Physiology, Faculty of Dentistry, Kyushu University, \\ Fukuoka 812, Japan
}

\begin{abstract}
A comparative investigation of the longitudinal and circular muscles in the pregnant rat uterus (10-15 days) was made by means of electrical and mechanical recordings. The response of the circular muscle strip was characterized in the following respects: application of stretch caused acceleration of spontaneous activity that was greater in extent than in the longitudinal muscle strip; tetanic contraction was not produced by repetitive stimuli in the range of $0.1-5 \mathrm{~Hz}$; slow potential was dominant in the circular muscle cells. The longitudinal contraction of the uterine segment occurred in synchronization with the change in the intraluminal pressure. Either the longitudinal stretch or the increase in the intraluminal volume caused the acceleration of synchronized activity. Stimulation of the longitudinal muscle caused membrane response in the circular muscle cells and vice versa, suggesting electrical interference between longitudinal and circular muscle cells.
\end{abstract}

The contractile response of the outer longitudinal muscle of guinea pig gut occurs independently of that of the inner circular muscle, unless it is controlled by intrinsic nerves (KoTtEGODA, 1969). On the other hand, it was reported that in the gut of cat the slow waves generated in the longitudinal muscle layer propagate into the circular muscle layer by electrotonic spreading possibly through the connecting muscle strands (KoBAYASHI et al., 1966). The mouse and rat myometria, in which the activities of the longitudinal and circular muscles occur in synchronization without the intervention of nerves (OsA, 1974b; OsA et al., 1974), appear to belong to the latter category of smooth muscle tissues.

In the present experiment, a comparative study of those muscles of pregnant rat was made by mechanical and electrical determinations, and the interaction between the two muscle layers was investigated.

Received for publication September 20, 1974

長 环朗, 片瀬 高 


\section{METHODS}

The longitudinal and circular muscle strips were obtained from rats pregnant for about 10-15 days. Occasionally, the strips were taken from the animal latest in term or in delivery. For mechanical recording alone, a thin strip about $0.5 \mathrm{~mm}$ wide and 5-10 $\mathrm{mm}$ long was adapted to a 2-mm diameter chamber. Electric pulses were applied by paired $\mathrm{Ag}-\mathrm{AgCl}$ rings placed at the ends of muscle strip, and the relative intensity (IR drop in the bathing solution) and the duration of stimulating pulses were measured on photographic records. For the electrical recording by microelectrode and electric stimulation using the partition chamber (AвE and TOMITA, 1968), strips of $3 \mathrm{~mm}$ wide and $7 \mathrm{~mm}$ long were used. Penetration of longitudinal or circular muscle cells was made from the serosal or endometrial side of the strip. Current pulse was applied along the longitudinal axis of the muscle strip or tangentially. The intention of this is to have the muscle cells belonging to the one muscle layer stimulated more effectively than those belonging to the other. Modification of the stimulating arrangements is described in RESULTS.

In some experiments, the simultaneous recording of the longitudinal contraction and the intraluminal pressure of the uterine segment was carried out, experimental arrangements being principally the same as those reported for the guinea pig intestine (TRENDELENBURG, 1917; KotTEGODA, 1969), i.e. the uterine segment having the longitudinal length of about $20 \mathrm{~mm}$ and the intraluminal volume of about $0.2-0.4 \mathrm{ml}$ at slack condition at $35^{\circ} \mathrm{C}$ was made, and the intraluminal pressure was conducted to the pressure strain gauge through a glass tube, filled with the Locke solution, to one end of which the segment was tied by thread. To maintain the intraluminal volume at a given level, the Locke solution was injected into or withdrawn from a thin rubber sac that fit inside the uterine segment. The other end was tied, hence forming a closed uterine sac, and was connected to a conventional strain gauge to measure the longitudinal contraction.

The physiological bathing solution was a modified Locke solution containing (mM): $\mathrm{NaCl} 154, \mathrm{NaHCO}_{3} 8, \mathrm{KCl} 5.6, \mathrm{CaCl}_{2} 2.2$ and glucose 11. The solution was equilibrated with a gas mixture of $97 \% \mathrm{O}_{2}$ and $3 \% \mathrm{CO}_{2}$. The final $\mathrm{pH}$ was 7.3 and the experiments were carried out at $35^{\circ} \mathrm{C}$. The drug used was tetrodotoxin (Sankyo Pharm. Co.). In occasional experiments, the tissue was treated with $0.5 \mathrm{~mm} \mathrm{Cd}$ for $1-2 \mathrm{~min}$ in order to suppress the mechanical activity (OsA, 1974a).

\section{RESULTS}

\section{Comparison of the contractile responses of the longitudinal and circular muscles}

Spontaneous activity of the longitudinal strip of pregnant rat myometrium varied from tissue to tissue. The spontaneous activity often disappeared gradually in the experimental chamber even when the stretch was applied in steps. In con- 
trast, the circular strip continued to exhibit spontaneous contractions during the experiments which lasted for 5-8 hr (Fig. 1). The most interesting finding at present was the relatively higher sensitivity of the circular strip to stretch in causing an increase in the frequency of contractions (Fig. 1b). The magnitude of contraction changed apparently obeying the length-tension relationship reported by previous authors (BRENDA et al., 1964; MASHIMA and YoshidA, 1965). The stretch relaxation of the muscle tone occurred very slowly. In this regard, the feature exhibits much resemblance to that observed in the whole rabbit uterus in vivo (SETEKLEIV, 1964).

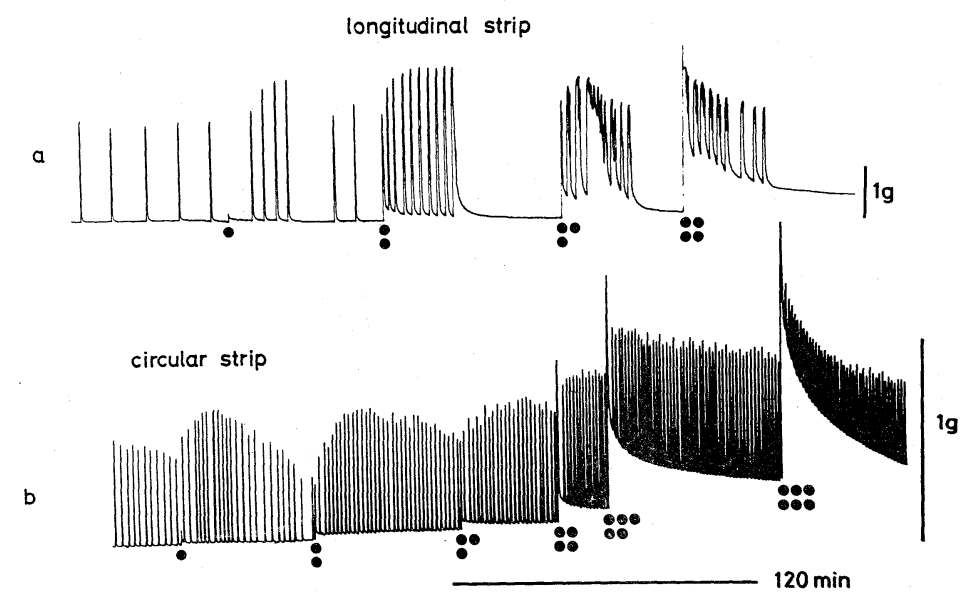

Fig. 1. Effects of stretch on the spontaneous contractions of the longitudinal (a) and the circular (b) muscle strips of the rat uterus. The initial length (slack length at $35^{\circ} \mathrm{C}$ ) of the strips was $6 \mathrm{~mm}$, and the stretch was applied quickly at the time indicated by filled circles. Each circle represents the addition of stretch by $3 \mathrm{~mm}$ and $2 \mathrm{~mm}$ for the longitudinal and circular muscle strips, respectively. Unless otherwise described in the legends, preparations were obtained from animals during a 10-15 days pregnancy.

In the experiment illustrated in Fig. 2 the strength-duration relationships of the circular and longitudinal muscle strips were measured, and the contractile response was taken as the indication of excitation. Because responses to the identical stimuli varied markedly when the interval was short ( $c f$. Fig. 3), the stimulus was applied $20-30 \mathrm{sec}$ after the response to the preceding stimulus terminated. The strength-duration curve did not show a single hyperbola, but stimulus intensity decreased steadily when the duration was long. Still, it is indicated that the relations were different for the longitudinal and circular muscle strips, i.e. stronger intensity was needed with a given stimulus duration in the circular muscle strip. The shortest duration for evoking the response with the present experimental apparatus was $0.5 \mathrm{msec}$ and $2.0 \mathrm{msec}$ for the longitudinal and circular muscle strips, respectively. The stimulus intensity was nearly the same 


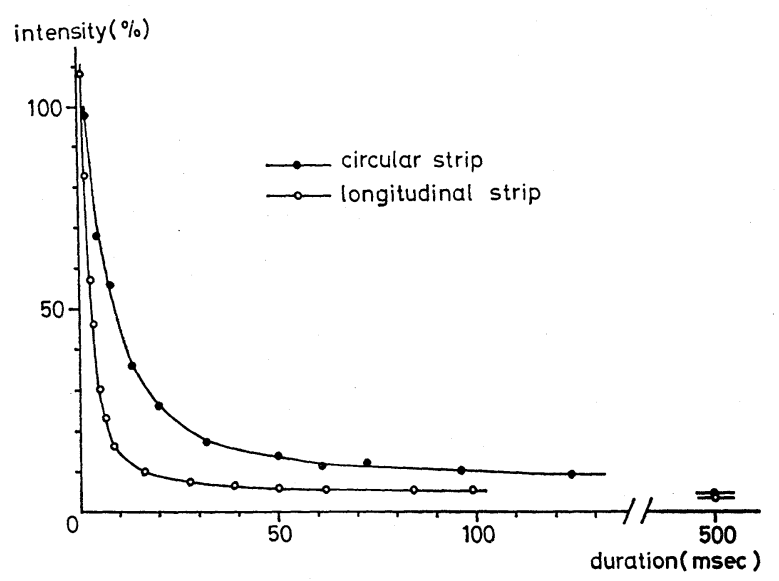

Fig. 2. Intensity-duration relationships of the circular (filled circle) and longitudinal (open circle) muscle strips measured for the contractile response. IR drop of $6 \mathrm{~V} / \mathrm{cm}$ in the bathing chamber is meant by $100 \%$ intensity.

for both strips when the duration was long (500 msec).

Even when the maximal stimulus was applied, the smaller response was produced in the longitudinal muscle strips unless the stimulus fit the time of raised excitability (Fig. 3a and b). An interesting contrast was encountered in the longitudinal and circular muscle strips when the tissues were stimulated repetitively with $1 \mathrm{~Hz}$ frequency. When stimuli 5 times stronger than the threshold strength $(100 \mathrm{msec})$ were applied to the circular muscle strip, the contractile response was triggered only by the initial stimulating pulse (d). With the same stimuli but with $10 \mathrm{msec}$ duration, the tetanic contraction was produced in the longitudinal muscle strip (c). The incapability of the circular muscle strip to produce the

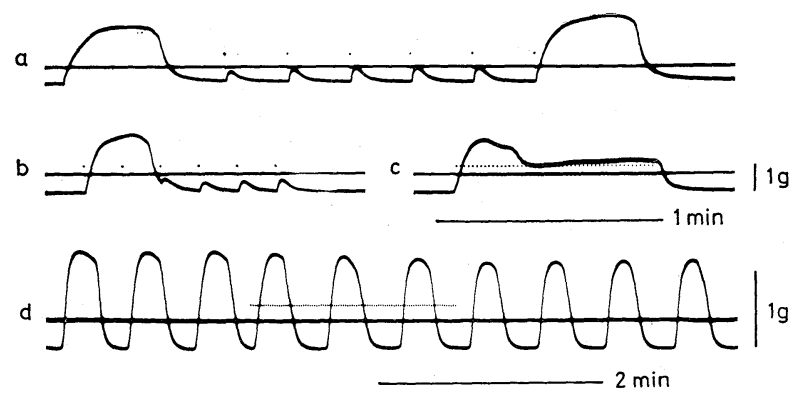

Fig. 3. Effects of the repetitive electric pulses on the contractile response of the longitudinal (a, b, and c) and circular (d) muscle strips. Upper traces show the stimulation. The duration of the pulses was $10 \mathrm{msec}$ and $100 \mathrm{msec}$ for the longitudinal and circular muscle strips respectively, and the intensity was 5 times stronger than the threshold. Frequency was $1 \mathrm{~Hz}$ for records $\mathrm{c}$ and $\mathrm{d}$. 
tetanic contraction was proved in other three tissues obtained from 10-15 days pregnant rats, using the various repetitive stimuli ranging $0.1-5 \mathrm{~Hz}$ and $50 \mathrm{msec}-$ $1.0 \mathrm{sec}$ duration. Application of tetrodotoxin $\left(10^{-7} \mathrm{~g} / \mathrm{ml}\right)$ did not affect those events. Because contractures produced in the isotonic $\mathrm{K}$ solution were almost the same for longitudinal and circular strips, the different behavior to electric stimuli is likely due to the membrane excitability.

Interaction between the longitudinal and circular muscle cells

It has been established that the increase in the intraluminal pressure represents circular constriction, hence the contraction of inner circular muscle layer (TRENDELENBURG, 1917). In order to investigate the effects of stretch under in vivo-like conditions, the uterine sac was prepared and the longitudinal contraction and the change in the intraluminal pressure were recorded simultaneously (Fig. 4). This experimental arrangement provides an additional information about the

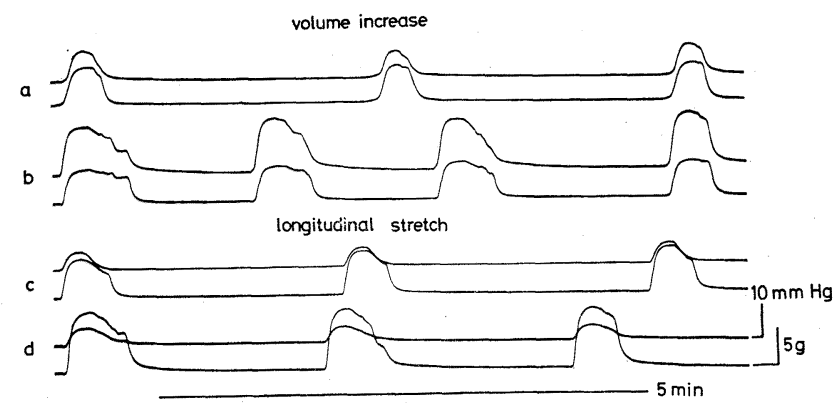

Fig. 4. Effects of the intraluminal volume increase and longitudinal stretch on the intraluminal pressure (upper traces) and longitudinal contraction (lower traces) of the uterine sac. $a$ and $c$ are the control responses of $b$ and $d$, respectively. The initial volume of the preparation was $0.4 \mathrm{ml}$ and $0.2 \mathrm{ml}$ Locke solution was injected into the intraluminal space (b). After the withdrawal of the added volume, the preparation was stretched $10 \mathrm{~mm}$ in a longitudinal direction (d;50\% increase of the initial length).

interaction between the activities of the longitudinal and circular muscles. When the intraluminal volume was increased by $50 \%$ of the initial value, the intraluminal pressure change alone was augmented, but the longitudinal length was not significantly changed. The frequency of contractions increased by about $25 \%$ of the control (b). On the other hand, $50 \%$ increase of the longitudinal length increased the frequency by $30 \%$ more than before and the magnitude of the longitudinal contraction was increased (d). The relation was essentially unaltered by the application of tetrodotoxin $\left(10^{-7} \mathrm{~g} / \mathrm{ml}\right)$ to the bathing solution. The main event of the above experiment was that the longitudinal contraction and the intraluminal pressure change occurred always in synchronization, and this was not due to nervous control. 


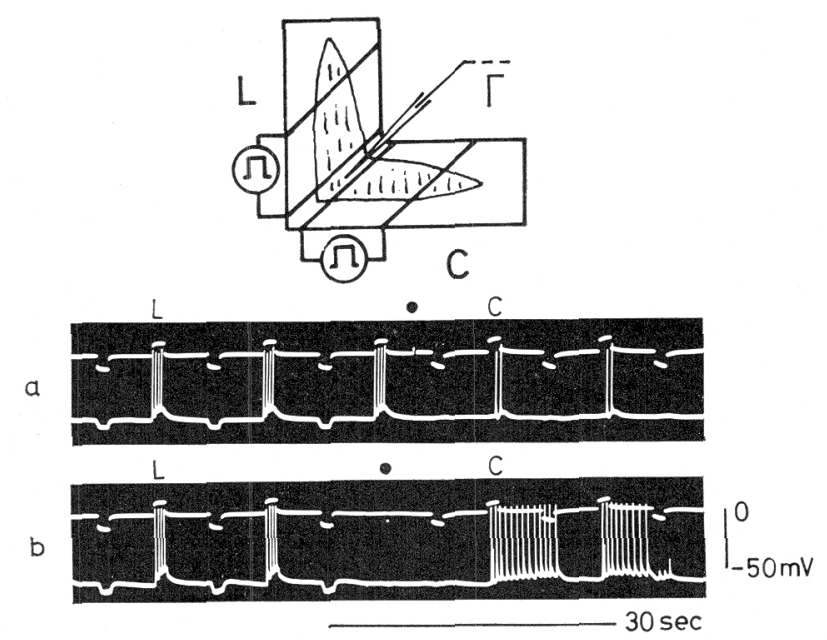

Fig. 5. Effects of external current application on the electrotonic potential and the spike generation. The stimulating chamber was composed of two identical chambers ( $\mathrm{L}$ and $\mathrm{C}$; see schematic drawing on top). Lines drawn in the preparation indicate the running direction of longitudinal muscle cells. Current was passed through two $\mathrm{Ag}-\mathrm{AgCl}$ plates which were placed in parallel $7 \mathrm{~mm}$ apart. Relative intensity of stimulus (upper beam) was measured by IR drop in the bathing solution. Recording partition at the corner of $\mathrm{L}$ was $0.5 \mathrm{~mm}$ in width. $\mathrm{L}$-shaped preparation was adapted serosal side upward in the partition chambers, so that the current was applied in parallel to the longitudinal muscle cells (L) or in a tangential direction (C). The response was recorded intracellularly from identical longitudinal muscle cells. The electric pulses were switched from $\mathrm{L}$ to $\mathrm{C}$ at the moment indicated by dots.

To inquire the electrical event underlying the synchronized contraction of the longitudinal and circular muscles, the electrical response to the current application using the partition chamber was investigated in the following experiments. The experimental arrangements are drawn schematically in Fig. 5. To suppress the mechanical activity, the tissue was treated with $0.5 \mathrm{~mm} \mathrm{Cd}$ for $1 \mathrm{~min}$, and a recording was made after $2 \mathrm{hr}$ 's rinse with the normal Locke solution. When addition of 5-7 $\mathrm{g}$ sucrose to the saline solution was used for the same purpose (ToMITA, 1966), a marked deterioration of the spike potential was caused. In response to the hyperpolarizing pulses applied to the longitudinal arm of the L-shaped preparation, the electrotonic potential was produced in the longitudinal muscle cell, and spikes were evoked by the depolarizing pulses (L). However, no measurable electrotonic potential was produced when the hyperpolarizing pulse was applied to the circular arm. However, spike potentials were produced by depolarizing pulses (C). The latency measured for the initial spike discharge was longer when the stimulation was applied to the circular arm. A similar event was observed in another cell (b), and in this case train discharge was produced by the depolarizing stimulus to the circular arm. Because the Cd-treatment immobilizes the tissue, 
the result may lead to a conclusion that the electrical response could be transmitted from the circular muscle cells over to the longitudinal muscle, and this was not by means of mechanical interference.

In accordance with the above observation, the frequency of bursts in the longitudinal muscle cells could be modified by application of the depolarizing

a

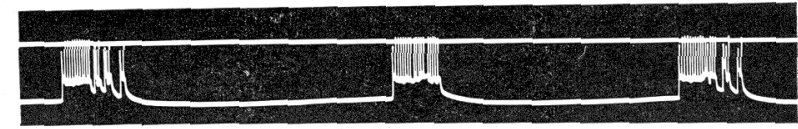

$b$
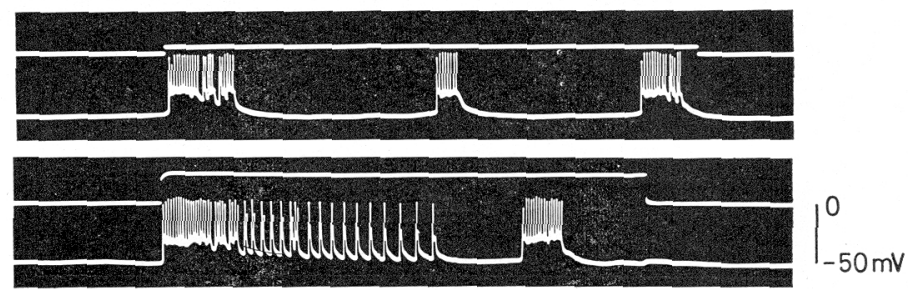

$1 \mathrm{~min}$

Fig. 6. Effects of the depolarizing long pulse stimulation applied to the circular muscle cells on the electrical response of the longitudina! muscle cell. The stimulating chamber was the conventional partition chamber (ABE and TомітA, 1968). The circular muscle strip was placed in the chamber serosal side up, so that the current was applied in parallel to the circular muscle cells and the electrical activity in the longitudinal muscle cell was recorded. The distance between the recording microelectrode and the nearer stimulating plate was $0.3 \mathrm{~mm}$. a, spontaneous electrical activity; b and c, responses to long current application of different intensities.

a

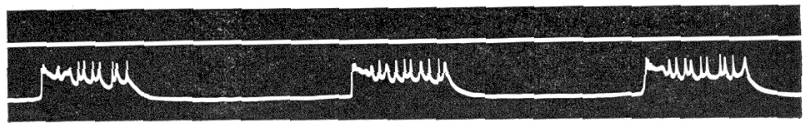

b

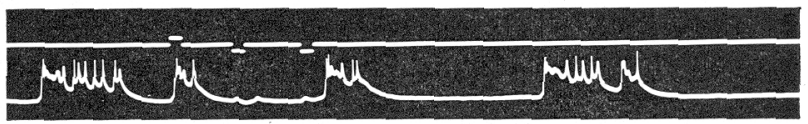

c

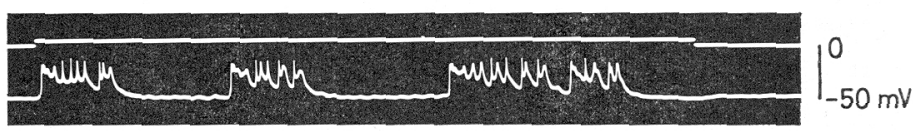

$30 \mathrm{sec}$

Fig. 7. Effects of the external current application applied to the longitudinal muscle cells on the electrical activity of the circular muscle cell. The longitudinal strip was placed in the partition chamber endometrial side up, so that the current was passed in parallel to the axis of longitudinal muscle cells and the electrical activity of circular muscle cell was recorded by the microelectrode. a, spontaneous activity; $b$, response to depolarizing or hyperpolarizing current pulse $(1 \mathrm{sec}) ; \mathrm{c}$, to the long depolarizing current. Note the small potentials in response to the hyperpolarizing short pulses (b), and to the depolarizing long pulse (c). 
current to the circular muscle layer (Fig. 6). The electrotonic depolarization was not produced even by strong current pulse (c). In a reversed manner, the current application to the longitudinal muscle cells affected the electrical activity in the circular muscle cell (Fig. 7). The hyperpolarizing current pulse applied in parallel to the longitudinal muscle cells did not produce the electrotonic potential change in the circular muscle cell, but the depolarizing pulse caused the generation of the action potential (b). The depolarizing long pulse current caused an acceleration of action potentials (c). Small potentials were produced in response to the hyperpolarizing short pulses (b), or during the application of the depolarizing current with long duration (c). It is of interest to speculate that the small potentials at present were due to the electrotonic spread of the spike potentials produced in the longitudinal muscle cells.

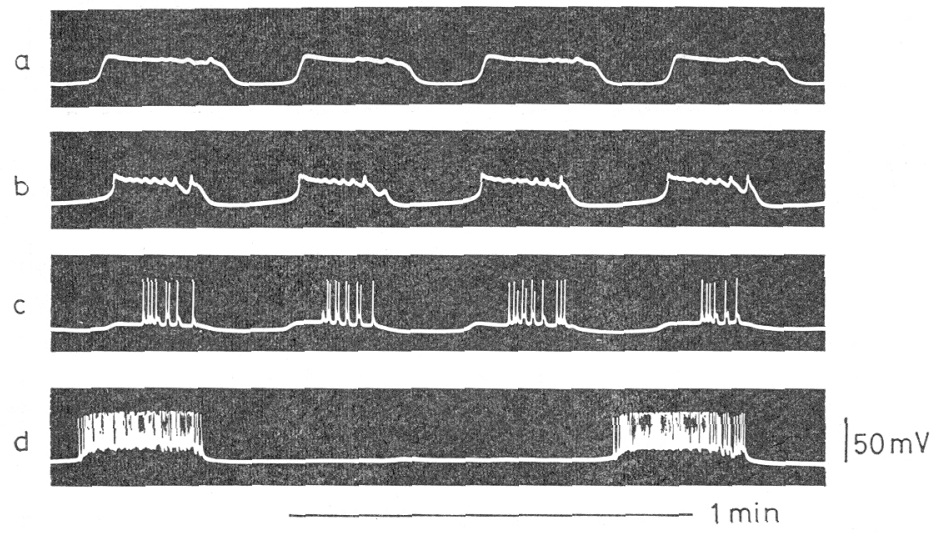

Fig. 8. Spontaneous electrical activities. The microelectrode was advanced from the endometrial side ( $a, b$, and c), and from serosal side (d), using different preparations from the same animal.

So far is known, the spike potential dominates the longitudinal muscle cells of the pregnant rat myometrium and the slow potential during burst discharge is in most cases preceded by the spike potential (MARSHALl, 1959; CASTEels and Kuriyama, 1965; TAYlor et al., 1970; OHASHI, 1970; ABE, 1971). The spontaneous action potentials illustrated in Fig. 8 were recorded from the myometrial tissues obtained from a pregnant rat (about 10 days). The burst of spike potentials shown in $d$ are typical of the response in the longitudinal muscle cell. In the cells shown in records $a$ and $b$, slow potentials were dominant, which is a general characteristic of the response in the circular muscle cells. As to the record c, an intermediary type of response between proper longitudinal and circular muscle cells might be noticed, because the amplitude of the slow potential was relatively small and this occurred prior to the spike generation. The spontaneous rhythm was identical with that of other circular muscle cells. 


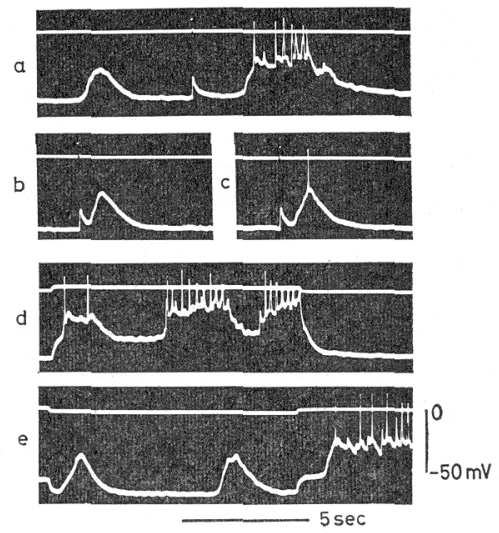

Fig. 9. Membrane activity of an intermediary type. Microelectrode was advanced from serosal side and stimulating current was applied in parallel to the longitudinal muscle cells. a, b, and c; responses to short pulse stimulation $(50 \mathrm{msec})$. d and $\mathrm{e}$; those to depolarizing or hyperpolarizing long pulse stimulation.

The responses shown in Fig. 9 were taken from another preparation. Although the response differed from that shown in Fig. $8 \mathrm{c}$ in minor points, those responses may well be classified as the intermediary response. Slow potentials were likely composed of two distinguishable ones (a), and the slow potential of shorter duration was evoked by the electrical stimulation (b), occasionally being supermounted by the spike potential (c). Application of long current pulse applied in parallel to the longitudinal muscle cells caused electrotonic change in the membrane potential. Depolarization accelerated the generation of action potentials (d), whereas hyperpolarization by the external current application caused the abolition of spikes leaving the slow potentials of shorter duration generated (e). It is also of interest to observe the small potentials during the current application of either polarity. Taking those small potentials to mean the electrotonic spread of the spike potentials produced in the longitudinal muscle cell ( $c f$. Fig. 7c), it may be assumed that this cell showing intermediary response belonged to the longitudinal muscle layer, or alternatively it belonged to specific cell group but was connected electrically to the neighboring longitudinal muscle cells.

The response of the circular muscle cells during the late pregnant stage

It was mentioned that the circular muscle strip of rat uterus (10-15 days pregnant) was characterized by the incapability of producing the tetanic contraction (Fig. 3d). However, the situation was different when the circular muscle strip from pregnant rat nearest term was used. The experiment shown in Fig. 10 was carried out on the tissue obtained during delivery. The tetanic contraction was produced by the repetitive stimuli with 3 times stronger intensity of the threshold (a; $1 \mathrm{~Hz}, 100 \mathrm{msec}$ ). As to the electrical events, spike potentials were much domi- 


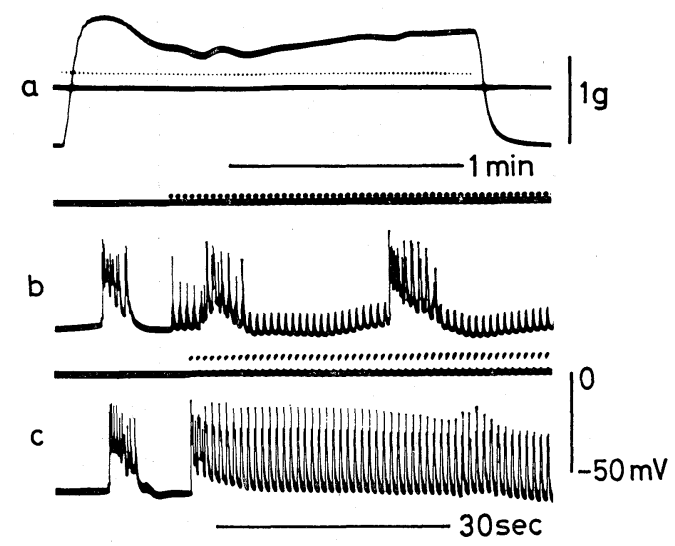

Fig. 10. Effects of repetitive stimuli $(1 \mathrm{~Hz}, 100 \mathrm{msec})$ on the circular strip taken from the pregnant rat during delivery. a, contractile response to 5 times stronger current intensity of the threshold; $b$, electrical responses to threshold intensity stimulation; $c$, those to 4 times stronger than the threshold. The microelectrode was penetrated from the endometrial side of the strip, and the stimulating current pulses were applied in parallel to the circular muscle cells. The distance between the recording and the nearer stimulating electrodes was $0.3 \mathrm{~mm}$.

nant in the spontaneous burst, and spike potential was produced by each tetanic pulse (c). The electrotonic potentials to the depolarizing pulses with threshold intensity indicate that the response was in fact from the circular muscle cell (b). Taking the results shown in Figs. 7, 8, and 10 altogether, it is suggested that the electrical activity of the longitudinal muscle cells exhibits less variability during pregnant stages, whereas that of the circular muscle cells is changeable.

\section{DISCUSSION}

Based on a precise observation on human myometrium and vas deferens by morphological methods, GOERTTLER $(1930,1934)$ proposed the 'spiral principle' of the muscle architecture in the visceral hollow organ. According to the theory, bundles of smooth muscle cells, except for those in gut (GOERTTLER, 1932), run spirally to the longitudinal axis of the organ, hence forming first the outer longitudinal, then inner circular and finally inner longitudinal muscle layers. The above finding and his own experiment on the contractile response, led him to dispute the traditional description in the textbooks. He said, "Erweiterung durch die Längsmuskulatur und Verengerung durch die Ringsmuskulatur alle denkbaren Mechanismen eines solchen lebendigen Rohrs wenigstens im Prinzip erschöpft seien. Diese Vorstellung ist aber nicht nur lückenhaft, sondern in vielen Fällen direkt falsch".

Goerttler seemingly assumed the homogeneous nature of spirally running muscle bundles, hence of longitudinal and circular muscles. However, the results 
reported in the present and previous papers favor the distinguishable properties between those muscles of pregnant rat and mouse 10 to 15 days pregnant. First, the electrical properties exhibited marked differences (Fig. 8). Second, the generation of spontaneous activity was more frequent and sensitive to the applied stretch in the circular muscle strip than in the longitudinal one (Fig. 1). Other events indicating the distinction are at present the differences in the strengthduration relationship and the response to tetanic stimuli (Figs. 3 and 4). In spite of the above-mentioned differences, the longitudinal and circular muscles contract in synchronization without an intervention of nerves.

Of possible intervening processes of transmission, mechanical interference can be excluded (Fig. 5), and the present results may prodive evidence that the electrical interference occurs between longitudinal and circular muscle cells (Figs. 5-8). It is tempting to assume that the muscle cells which showed an intermediary type of electrical response (Fig. 8c) took the place of the interconnecting system of the transmission of excitation between the longitudinal and circular muscles. The finding of the localization of this type of muscle cells by topical staining might be essential to substantiate this speculation. In the intermediary response, the membrane activity was typified by the generation of spike and slow potentials which could be dissociated (Fig. 9). How far the electrical responses were due to the electrotonic spread from the neighboring muscle cells or to the active response caused by the change in ionic permeability remains quite unknown. At present, the mosaic nature of the responses might be presumed in these intermediary muscle cells. Thus, the classical concept of the continuity of the longitudinal and circular muscles of visceral organs (GoERTTLER, 1930, 1934) is now presumably interpreted to indicate that the electrical properties of the proper longitudinal and circular muscles differ, but these maintain the electrical connection by muscle cells which exhibited an electrically intermediary response in the case of rat myometrium.

The observation that the spontaneous activity of the longitudinal muscle strip of rat uterus was often rare ( $c f$. Fig. 1) was an experimental one, but it occurred vigorously in the recording chamber used for microelectrode technique in which both muscle layers were stretched two-dimensionally. Concerning the spontaneous activity which was present in either small or large myometrial pieces from any site of rat uterus, it seems likely that the muscle cell group having the fastest spontaneous rhythm takes the role of pacemaker in a given dimension of the preparation. Because the spontaneous contractions of the circular muscle strip was usually more frequent and they were more sensitive to stretch (Fig. 1), the pacemaker activity in the circular muscle cells might be physiologically more significant.

In the smooth muscle tissues of visceral type, spike generation is likely essential to achieve the non-decremental propagation of excitation (OSA and KURIYAMA, 1970). For this reason, it is also of interest to note that the circular muscle obtained from the animal during delivery produced dominant spike potentials and 
developed tetanic contraction (Fig. 10). The physiological significance of the change in the membrane property of the circular muscle in the performance of the mechanical function of the pregnant uterine tissue should be examined in further experiments.

The authors express their appreciation to Prof. H. Kuriyama for the critical examination of the manuscript, and to Prof. M. Miyoshi, Department of Anatomy, Fukuoka University, for informing us about the morphological literature.

\section{REFERENCES}

ABE, Y. (1971) Effects of changing the ionic environment on passive and active membrane properties of pregnant rat uterus. J. Physiol., 214: 173-190.

AbE, Y. and Tomita, T. (1968) Cable properties of smooth muscle. J. Physiol., 196: 87-100.

BRenda, M., SCHOFIELD, M., and Wood, C. (1964) Length-tension relation in rabbit and human myometrium. J. Physiol., 175: 125-133.

Casteels, R. and Kuriyama, H. (1965) Membrane potential and ionic content in pregnant and non-pregnant rat myometrium. J. Physiol., 177: 263-287.

GoertTLeR, K. (1930) Die Architektur der Muskelwand des menschlichen Uterus und ihre funktionelle Bedeutung. Morph. Jahrb., 65: 45-128.

GoertTler, K. (1932) Der konstruktive Bau der menschlichen Darmwand. Morph. Jahrb., 69: 329-379.

Goerttler, K. (1934) Die Konstruktion der Wand des menschlichen Samenleiters und ihre funktionelle Bedeutung. Morph. Jahrb., 74: 550-580.

Kobayashi, M., NagaI, T., and Prosser, C. L. (1966) Electrical interaction between muscle layers of cat intestine. Am. J. Physiol., 211: 1281-1291.

KotTEGODA, S. R. (1969) An analysis of possible nervous mechanisms involved in the peristaltic reflex. J. Physiol., 200: 687-712.

Mashima, H. and Yoshida, T. (1965) Effect of length on the development of tension in guinea pig's taenia coli. Jap. J. Physiol., 15: 463-477.

MARSHALL, J. (1959) Effect of estrogen and progesterone on single uterine muscle fibers in the rat. Am. J. Physiol., 197: 935-942.

OHASHI, H. (1970) Effects of changes of ionic environment on the negative after-potential of the spike in rat uterine muscle. J. Physiol., 210: 785-797.

OsA, T. (1974a) Modification of the mechanical response of the smooth muscles of pregnant mouse myometrium and guinea pig ileum by cadmium and manganese ions. Jap. J. Physiol., 24: 101-117.

OsA, T. (1974b) An interaction between the electrical activities of longitudinal and circular smooth muscles of pregnant mouse uterus. Jap. J. Physiol., 24: 189-203.

Osa, T. and KuriYama, H. (1970) The membrane properties and decremental conduction of excitation in the fundus of guinea-pig stomach. Jap. J. Physiol., 20:626-639.

Osa, T., KatASE, T., and ShiBATA, T. (1974) Inhibitory action of the human and rat placental extracts on myometrial activities of mouse and rat. Jap. J. Physiol., 24: 433-450.

SetekLeiv, J. (1964) Uterine motility of the estrogenized rabbit. II. Response to distension. Acta Physiol. Scand., 62: 79-93.

Taylor, G. S., Paton, D. M., and Daniel, E. E. (1970) Characteristics of electrogenic sodium pumping in rat myometrium. J. Gen. Physiol., 56: 360-375.

Tomita, T. (1966) Electrical responses of smooth muscle to external stimulation in hypertonic solution. J. Physiol., 183: 450-468.

Trendelenburg, P. (1917) Physiologische und pharmakologische Versuche über die Dünndarmperistaltik. Arch. Exp. Pathol. Pharmakol., 81: 55-129. 